\title{
Impact of two light programs and two levels of dietary tryptophan for weanling piglets
}

\author{
Lívea Maria Gomes ${ }^{\mathrm{a}, *}$, Gabriela de Mello Miassi ${ }^{\mathrm{a}}$, Luan Sousa dos Santos ${ }^{\mathrm{a}}$, \\ Mayra Anton Dib Saleh ${ }^{\mathrm{a}}$, José Roberto Sartori ${ }^{\mathrm{b}}$, Marcos Lívio Panhoza Tse ${ }^{\mathrm{a}}$, Dirlei Antonio Berto ${ }^{\mathrm{a}}$ \\ ${ }^{a}$ Department of Animal Production, UNESP - São Paulo State University, Dr José Barbosa de Barros Street, 1780, Lageado Experimental Farm, Botucatu, São Paulo \\ 18610-307, Brazil \\ ${ }^{\mathbf{b}}$ Department of Breeding and Animal Nutrition, UNESP - São Paulo State University, Dr José Barbosa de Barros Street, 1780, Lageado Experimental Farm, Botucatu, São \\ Paulo 18610-307, Brazil
}

\section{A R T I C L E I N F O}

\section{Keywords:}

Amino acid

Welfare

Feeding behavior

Photoperiod

Swine

\begin{abstract}
A B S T R A C T
Photoperiod and supplementary tryptophan can attenuate the effects of stressful weaning. However, few studies have evaluated tryptophan metabolism in the presence of light. This study aimed to evaluate the effects of tryptophan levels (TL) on the diet of weanling piglets submitted to different light programs (LP). Seventy-two piglets weaned at 21 days of age (starting weight $6.6 \pm 2.33 \mathrm{~kg}$ ) were used. The experimental design consisted of randomized blocks with 24 days of duration in a $2 \times 2$ factorial arrangement. Two LP were used: 12-h or 23-h light/day. Two digestible TL were used: $2.6 \mathrm{~g}$ or $5.2 \mathrm{~g}$ of Trp/ $\mathrm{kg}$ feed on pre-starter I diet (from 0 to 14 trial days) and $2.4 \mathrm{~g}$ or $4.8 \mathrm{~g}$ of Trp/ $\mathrm{kg}$ feed on pre-starter II diet (from 15 to 24 trial days). Six replicates of three animals per treatment were performed. Growth performance, blood glucose, plasma cortisol profiles and animal behavior were assessed. Blood glucose was measured on experimental days 0 and 24, and cortisol was measured on days 0 and 8. Behavior was observed on days 2, 9, 16 and 23. Neither growth performance nor blood glucose were affected by the interaction between LP and TL. The treatments did not influence daily weight gain, daily feed intake and blood glucose during the periods of 0-14, and 0-24 days. Feed:gain ratio improved during the 0-14 days period for piglets receiving 12-h light/day. The treatments did not influence the frequency of "moving" behaviors. However, the interaction between LP and TL affected the plasma cortisol and frequency of "feeding" and "lying" behaviors. Piglets that received the highest TL had lower plasma cortisol levels, reduced "feeding" behaviors and increased "lying" behaviors, compared to animals that received normal TL, when subjected to LP of 23-h light/day. The results suggest that use of LP of $23 \mathrm{~h}$ light/day is not indicated for piglets.
\end{abstract}

\section{Introduction}

Pigs (Sus scrofa domesticus) are gregarious animals that tend to maintain a stable social hierarchy. However, when litters are separated after weaning, the pre-established social group is altered to form groups of animals homogeneous in weight and gender. This post-arrangement of animals triggers an increase in the number of agonistic interactions and fights to promote stabilization of the new social hierarchy (Andersen et al., 2000). In addition, the stress of weaning leads to anomalous behaviors in animals in an attempt to suppress frustration, hunger, fear or monotony (Hemsworth and Coleman, 2011), and results on low feed intake, an unbalanced microbiota with alterations in the intestinal mucosa, depression of immune response and diarrheas that compromise growth (Mahan, 1991).
Dietary composition may be manipulated to alleviate the negative aspects of weaning stress. Tryptophan is the fourth limiting amino acid for piglets fed soybean and corn-based meals. It is essential for protein synthesis, is the precursor of important metabolites, such as serotonin and melatonin that are involved in regulation of gastrointestinal function, expression and secretion of ghrelin, feed intake stimulation, temperature regulation and immune response (Ning and Qian, 2008; Pereira et al., 2008; Rossi and Tirapegui, 2004; Zhang et al., 2007). When tryptophan is supplemented in diet at levels that exceed the recommendations for maximum growth, it can influence susceptibility to stress and pig behavior (Adeola and Ball, 1992; Van Hierden et al., 2004), and it may be useful to reduce stress and improve the pigs' welfare during specific periods, such as weaning (Koopmans et al., 2005; Martínez-Trejo et al., 2009; Sève et al., 1991).

\footnotetext{
* Corresponding author.

E-mail addresses: livea_pitti@hotmail.com (L.M. Gomes), d.berto@unesp.br (D. Antonio Berto).
} 
As the photoperiod influences well-being, behavior and animal reproduction (Peltoniemi et al., 2000), artificial lighting has been used in several stages of pig farming. It can stimulate earlier feed intake in weaned piglets (Bruininx et al., 2001), and improve their growth performance (Glatz, 2001; Reiners et al., 2010; Sousa Júnior et al., 2011). On the other hand, darkness periods are necessary for production and release of melatonin (Maganhin et al., 2008) that acts on digestive system and works as an antioxidant, besides regulating the immune system, sleep-wake cycles and hormone concentration (Amaral et al., 2014; Paredes et al., 2009).

Tryptophan is a precursor of serotonin, which in turn is produced in the light phase and posteriorly converted to melatonin during the dark phase. Thus, a relationship between level of dietary tryptophan and photoperiod may exist, such that both act on the regulation of stress response to weaning. This study evaluated the effects of increasing dietary TL (by 100\%) on weaning pigs treated under different LP (12L:12D and 23L:1D). We tested if this increase was capable of reducing/neutralizing the negative effects of weaning over daily feed intake, daily weight gain, feed:gain ratio, blood glucose, plasma cortisol profile and behavior.

\section{Material and methods}

Experiments were carried out at São Paulo State University “Júlio de Mesquita Filho" - UNESP, Faculty of Veterinary Medicine and Animal Science - FMVZ, Botucatu Campus, located in the South-central region of the São Paulo State, latitude $22^{\circ} 53^{\prime} 09^{\prime \prime}$ (S), longitude $48^{\circ} 26^{\prime} 42^{\prime \prime}$ (W) and altitude of $804 \mathrm{~m}$. All procedures were approved by the Ethics Committee for the Use of Animals of the Institution (protocol number 30/2014)

\subsection{Facilities and experimental diets}

Seventy-two hybrid piglets from a commercial line (Landrace $\mathrm{x}$ Large White) weaned at an average age of 21 days were selected according to gender (36 castrated males and 36 females) and with an average weight of $6.6 \pm 2.33 \mathrm{~kg}$. The piglets were allocated into blocks using the sex and weight criteria, so that three blocks of females and three blocks of castrated males were assembled and the mean weight of the blocks was the most homogeneous as possible among experimental groups. They were housed in two $0.9 \times 2.6 \mathrm{~m}$ bioclimatic chambers, in compact floor pens with bedding of shavings of approximately $3.0 \mathrm{~cm}$, equipped with feeders and nipple-type drinkers.

The internal temperature of the chamber was set at $26^{\circ} \mathrm{C}$ for the first 14 days and at $23^{\circ} \mathrm{C}$ for the last 10 days (this condition was considered a thermo-neutral zone for the animals). Exhaust fans were used for internal ventilation of the chambers in the hottest hours of the day. The light program was applied using incandescent light bulbs with constant luminosity of $40 \mathrm{~lx}$ (minimum required) at the level of the animals' eyes. The portable digital lux meter Instrutherm ', model LD-300 (Instrutherm Measuring Instruments Ltda, São Paulo, SP, Brazil) with a $0.1-50,000 \mathrm{~lx}$ range was used to measure luminosity. $\mathrm{HOBO}^{\circ}$ sensors (data logger-type) (Onset Computer Corporation, Bourne, MA, USA) were installed to monitor undesirable oscillations in environmental variables. These were positioned as close as possible to the animals, but out of their reach.

The experiment lasted 24 days. During this period, piglets received water ad libitum and the two types of diet, according to the following feeding programs: pre-starter diet I (for 21- to 35-day-old piglets), and pre-starter diet II (for 36- to 45-day-old piglets). The dietary formulation for each studied phase responded to the minimum nutritional requirements proposed by Rostagno et al. (2011), and the diets were provided ad libitum. Table 1 shows the calculated nutritional composition (\%) for each diet.

The experiment followed a randomized-complete blocks design, in a $2 \times 2$ factorial arrangement, with Trp level (TL) as the first factor, and
Table 1

Nutritional composition of pre-starter I and II diets.

\begin{tabular}{|c|c|c|c|c|}
\hline \multirow[t]{2}{*}{ Ingredients (\%) } & \multicolumn{2}{|c|}{ Pre-starter I } & \multicolumn{2}{|c|}{ Pre-starter II } \\
\hline & $\mathrm{NT}^{\mathrm{a}}$ & $\mathrm{HT}^{\mathrm{a}}$ & $\mathrm{NT}^{\mathrm{a}}$ & $\mathrm{HT}^{\mathrm{a}}$ \\
\hline Corn grits & 50.000 & 50.000 & 55.230 & 55.230 \\
\hline Soybean meal (45\%) & 20.000 & 20.000 & 24.00 & 24.00 \\
\hline Whey powder & 8.000 & 8.000 & 4.000 & 4.000 \\
\hline Sugar & 4.000 & 4.000 & 3.000 & 3.000 \\
\hline Blood plasma & 4.000 & 4.000 & 2.500 & 2.500 \\
\hline Maltodextrin & 5.000 & 5.000 & 2.500 & 2.500 \\
\hline Soybean-oil & 2.385 & 2.385 & 2.700 & 2.700 \\
\hline Corn gluten meal $(60 \%)$ & 1.500 & 1.500 & 1.500 & 1.500 \\
\hline Limestone & 0.800 & 0.800 & 0.920 & 0.920 \\
\hline Dicalcium phosphate & 1.500 & 1.500 & 1.400 & 1.400 \\
\hline Salt & 0.350 & 0.350 & 0.350 & 0.350 \\
\hline L-Lys (78\%) & 0.670 & 0.670 & 0.540 & 0.540 \\
\hline DL-Met $(99 \%)$ & 0.260 & 0.260 & 0.190 & 0.190 \\
\hline L-Thr $(98.5 \%)$ & 0.240 & 0.240 & 0.180 & 0.180 \\
\hline L-Trp $(98 \%)$ & 0.060 & 0.330 & 0.036 & 0.286 \\
\hline L-Ile $(98 \%)$ & 0.140 & 0.140 & 0.040 & 0.040 \\
\hline L-Val $(96.5 \%)$ & 0.180 & 0.180 & 0.100 & 0.100 \\
\hline Choline chloride $(60 \%)$ & 0.040 & 0.040 & 0.040 & 0.040 \\
\hline Kaolin & 0.270 & 0.000 & 0.025 & 0.000 \\
\hline Zinc oxide $(72 \%)$ & 0.340 & 0.340 & 0.200 & 0.200 \\
\hline Copper sulfate & 0.000 & 0.000 & 0.060 & 0.060 \\
\hline B.H.T. ${ }^{b}$ & 0.015 & 0.015 & 0.015 & 0.015 \\
\hline Mineral $^{\mathrm{c}}$ and vitamin ${ }^{\mathrm{d}}$ premixes & 0.250 & 0.250 & 0.250 & 0.250 \\
\hline \multirow[t]{2}{*}{ Total } & 100.000 & 100.000 & 100.000 & 100.000 \\
\hline & \multicolumn{4}{|c|}{ Calculated values } \\
\hline Metabolizable energy (kcal/kg) & 3,394 & 3,410 & 3,374 & 3,388 \\
\hline Crude protein $(\%)$ & 18.950 & 19.180 & 19.250 & 19.470 \\
\hline Total Ca (\%) & 0.840 & 0.840 & 0.830 & 0.830 \\
\hline Available P (\%) & 0.450 & 0.450 & 0.410 & 0.410 \\
\hline Digestible Lys (\%) & 1.450 & 1.450 & 1.330 & 1.330 \\
\hline Digestible Met (\%) & 0.510 & 0.510 & 0.450 & 0.450 \\
\hline Digestible Met + Cys (\%) & 0.810 & 0.810 & 0.750 & 0.750 \\
\hline Digestible Thr (\%) & 0.910 & 0.910 & 0.840 & 0.840 \\
\hline Digestible Trp (\%) & 0.260 & 0.520 & 0.240 & 0.480 \\
\hline Total $\mathrm{Na}(\%)$ & 0.340 & 0.340 & 0.260 & 0.260 \\
\hline
\end{tabular}

a NT = normal Trp levels, as recommended by Rostagno et al. (2011); HT = high Trp levels (a 100\% higher level).

b B.H.T.: butylated hydroxytoluene antioxidant.

c Mineral premix provided per kg of feed: $100 \mathrm{mg}$ Fe, $10 \mathrm{mg} \mathrm{Cu}, 0.3 \mathrm{mg} \mathrm{Se}$, $40 \mathrm{mg}$ Mn, $100 \mathrm{mg} \mathrm{Zn}, 1 \mathrm{mg}$ Co, $1.5 \mathrm{mg}$ I.

${ }^{d}$ Vitamin premix provided per kg of feed: 9000 I.U. vit. A, 2250 I.U. vit. $D_{3}$, $22.5 \mathrm{mg}$ vit. E, $22.5 \mathrm{mg}$ vit. $\mathrm{K}_{3}, 2.03 \mathrm{mg}$ vit. $\mathrm{B}_{1}, 6 \mathrm{mg}$ vit. $\mathrm{B}_{2}, 3 \mathrm{mg}$ vit. $\mathrm{B}_{6}, 30 \mu \mathrm{g}$ vit. $\mathrm{B}_{12}, 0.9 \mathrm{mg}$ folic acid, $14.03 \mathrm{mg}$ pantothenic acid, $30 \mathrm{mg}$ niacin, $0.12 \mathrm{mg}$ biotin, $400 \mathrm{mg}$ choline chloride.

light program (LP) as the second. Two TL were used: normal level, which contained $0.26 \%$ and $0.24 \%$ of digestible Trp on pre-starter I and II diets respectively, as recommended by Rostagno et al. (2011), and a $100 \%$ higher level. Two light regimes were used: 12 -h of light and 12-h of dark (12L:12D) and 23-h of light and $1 \mathrm{~h}$ of dark (23L:1D). In the 23L:1D program, lights were kept on from $7: 00 \mathrm{~h}$ to $6: 00 \mathrm{~h}$. In the 12L:12D program, lights were kept on from 7:00 h to 19:00 h. Six replicates (blocks) of three animals per treatment were used per experimental unit. Piglet weight and gender were used as criteria for allocating animals into blocks.

\subsection{Growth performance and stress indicators}

To determine weight gain, animals were weighed in the beginning (day-0, after weaning) and on days 14 and 24 of the experiment. Feed intake was calculated for each stage, by subtracting the leftovers at the end of each experimental stage from the provided feed quantity. Feed:gain ratio was calculated by the relationship between feed intake and animal weight gain.

Plasma cortisol levels were measured on blood collected from the vena cava of six randomly chosen animals (for each treatment) using 
siliconized needles $\left(21 \mathrm{G} \times 1^{\prime \prime}\right)$ with a vacuum system and $10 \mathrm{~mL}$ vacuum tube with 3\% EDTA (Becton Dickinson Vacutainer Systems, Franklin Lakes, NJ, USA). Collections were made one day prior to weaning (d-1), and on the day 8 post-weaning (d-8), between $8: 00 \mathrm{~h}$ and 9:00 h, ensuring the absence of endogenous cortisol peaks. To avoid additional stress, piglets were taken individually to a separate room and the sampling was performed as quickly as possible.

Blood samples were taken to the clinical analysis laboratory and centrifuged $(2000 \times g$ for $10 \mathrm{~min}$ ) to separate the plasma, which was frozen in labeled $1.5 \mathrm{~mL}$ tubes. Plasma cortisol dosage was performed using a $5 \mathrm{nM}$-sensitivity radioimmunoassay kit (Beckman-Coulter Inc., Pasadena, CA, USA) and the reading performed on the automatic gamma counter Wizard ${ }^{\circledR}$, model 1470 (PerkinElmer, Waltham, MA, USA) coupled to the software MultCalc (Schreiber Engineering Ltda, Florianópolis, SC, Brazil). The cortisol analysis period was chosen based on the results of Adeola and Ball (1992), who reported that the increase in serotonin production after tryptophan-supplemented feeding takes on average five days. We included three more days to ensure that all animals would have initiated feeding by then, and performed collection of blood on day 8.

To determine glucose levels, blood was collected from six randomly chosen animals (for each treatment) by puncturing the marginal artery of the ear with a needle. Measurements were performed one day prior to weaning (d-1) and on the last day of experiments (d-24), always at 20:00 h, using the digital glucose meter Accu-Check ${ }^{\circledR}$ Performa (Roche Diagnostics, Jaguaré, SP, Brazil). Measurements on the last day of experiment were used to evaluate the duration and amplitude of weaning stress and organism adaptability.

Growth performance, cortisol and glucose data were submitted to GLM variance analysis from SAS ${ }^{\circ}$ (SAS Inst. Inc., Cary, NC, USA) statistical package, and the averages were compared using the $F$ test $(5 \%$ significance). Basal glucose and plasma cortisol concentrations measured one day prior to weaning (day-1) were used for final adjustment of averages by covariate.

\subsection{Behavior}

Two mini cameras were strategically positioned in the ceiling at the extreme sides of each of the two bioclimatic chambers (four in total) in equivalent locations, always following the same pattern height and distance of the observed pens to obtain the widest field of vision possible and to register the behavior of the whole group of piglets. The cameras contained an infrared lamp with $850 \mathrm{~nm}$ of wavelength (not visible to animals), to allow recording of the facilities in the absence of lighting. The cameras were connected to a multiplexer that monitored the images and, simultaneously, recorded them in a time-lapse manner for $24 \mathrm{~h}$.

Behavior sampling of each animal was registered according to an ethogram (Table 2), using instantaneous scan sampling method described by Martin and Bateson (2008). A continuous 24-h register in 15min intervals was used for each animal, on days 2, 9, 16 and 23. Only one person performed the behavior observations, minimizing the errors introduced by different observers.

The number of time each behavior category was observed, it was converted to frequencies to perform statistical analysis of the data.
Shapiro-Wilk's test confirmed that data followed a normal distribution. Data were analyzed using the MIXED procedure of SAS (SAS Inst. Inc., Cary, NC, USA). $P$-values $\leq 0.05$ were considered statistically significant.

\section{Results}

\subsection{Growth performance}

No interaction $(P>0.05)$ between LP and TL in the daily feed intake (DFI), daily weight gain (DWG) and feed:gain ratio (F:G) were detected (Table 3). In the 0-14-day and 0-24-day periods, treatments produced no effect on DWG and DFI. F:G was improved by $7 \%$ $(P<0.05)$ in the $0-14$ days period for piglets receiving $12 \mathrm{~h}$ of light/ day compared to those receiving $23 \mathrm{~h}$ of light/day, but was not influenced in the longer period ( $0-24$ days).

\subsection{Stress indicators}

TL did not interact with the LP and the treatments produced no effect $(P>0.05)$ on blood glucose, but there was an interaction $(P<0.0002)$ of the factors over the plasma cortisol at experimental day-8 (Table 4). Piglets receiving a normal TL diet $(2.6 \mathrm{~g} \mathrm{Trp} / \mathrm{kg})$ and 23-h of light/day had higher plasma cortisol levels than those receiving $12 \mathrm{~h}$ of light/day $(P<0.0001)$. High dietary TL $(5.2 \mathrm{~g}$ Trp $/ \mathrm{kg})$ increased $(P<0.03)$ the concentration of plasma cortisol for piglets under a regime of $12 \mathrm{~h}$ of light/day.

\subsection{Behavior}

Treatments did not interact or produce any effect on "moving" behavior $(P>0.05)$ (Table 5). There was an interaction between the factors TL and LP over the behaviors "feeding" $(P<0.006)$ and "lying" $(\mathrm{P}<0.02)$. Piglets receiving $23 \mathrm{~h}$ of light/day and fed a normal TL-diet had higher frequency of "feeding" behaviors $(\mathrm{P}<0.006)$ and lower frequency of "lying" behaviors $(P<0.02)$, compared to piglets receiving $23 \mathrm{~h}$ of light/day and fed high TL-diets. They also had higher "feeding" behaviors compared to piglets receiving 12-h of light/day and fed a normal TL diet. LP did not influence the frequencies of "feeding" and "lying" behaviors when piglets were fed a diet containing the highest level of tryptophan (Table 5).

\section{Discussion}

This study is a preliminary analysis relating Trp metabolism to the photoperiod to which animal is exposed. Therefore, the use of bioclimatic chambers not only granted us control over the light hours to which animals would be exposed, but also gave us the possibility of manipulating environmental factors such as temperature, humidity and ventilation. If not properly controlled, these factors could have masked the effects in the variables studied. Our results highlight valuable experimental observations that can now serve as the basis for the design of novel studies in the context of commercial pig farming. The housing environment, with controlled temperature and bedding availability, was probably less stressful than commercial farms. According to

Table 2

Animal behaviors observed during the nursery phase and their definitions.

Source: Adapted from Hurnik et al. (1995), Hötzel et al. (2004, 2010) and Reiners et al. (2010).

\begin{tabular}{|c|c|}
\hline Behavior & Definition \\
\hline Moving & $\begin{array}{l}\text { Animal is standing up, still or walking; revolving the soil, walls, railings or feeders; attacking or being attacked by another animal, biting, pushing another animal } \\
\text { aggressively or in retaliation to an aggressive attack; interacting with the partner in the pen using the snout, belly-nosing, biting; running and following the partner of } \\
\text { the pen; running against the pen's railings, supporting the front paws in the cell or jumping in the direction of the pen's borders, attempting to escape. }\end{array}$ \\
\hline Lying & Animal lying down, with the eyes closed or opened; seating on the back paws; \\
\hline Feeding & Animal with the head inside the feeder; with the mouth in contact with the drinker's nipple. \\
\hline
\end{tabular}


Table 3

Effects of light programs (LP) and dietary Trp levels on piglet's growth performance at nursery phase.

\begin{tabular}{|c|c|c|c|c|c|c|c|c|c|}
\hline \multirow[t]{2}{*}{ Period days } & \multirow[t]{2}{*}{ Variable } & \multirow[t]{2}{*}{ LP $12 / \mathrm{NT}^{\mathrm{a}}$} & \multirow[t]{2}{*}{$\mathrm{LP} 12 / \mathrm{HT}^{\mathrm{a}}$} & \multirow[t]{2}{*}{$\mathrm{LP} 23 / \mathrm{NT}^{\mathrm{a}}$} & \multirow[t]{2}{*}{$\mathrm{LP} 23 / \mathrm{HT}^{\mathrm{a}}$} & \multirow[t]{2}{*}{ SEM $^{\mathrm{c}}$} & \multicolumn{3}{|l|}{$P$-values } \\
\hline & & & & & & & LP effect & TL effect & $\mathrm{LP} * \mathrm{TL}$ \\
\hline \multirow[t]{3}{*}{${ }^{\#} 0-14$} & DFI (g) & 438.3 & 433.0 & 450.8 & 418.5 & 11.8 & $\mathrm{NS}^{\mathrm{d}}$ & NS & NS \\
\hline & DWG (g) & 317.0 & 318.0 & 306.8 & 286.0 & 9.6 & NS & NS & NS \\
\hline & $F: G^{b}$ & $1.38 \mathrm{~A}$ & $1.36 \mathrm{~A}$ & $1.47 \mathrm{~B}$ & $1.46 \mathrm{~B}$ & 0.02 & 0.02 & NS & NS \\
\hline \multirow[t]{3}{*}{${ }^{\#} 0-24$} & DFI (g) & 662.7 & 663.2 & 652.0 & 598.0 & 16.1 & NS & NS & NS \\
\hline & DWG (g) & 409.0 & 414.8 & 404.2 & 384.0 & 7.4 & NS & NS & NS \\
\hline & $\mathrm{F}: \mathrm{G}$ & 1.62 & 1.59 & 1.61 & 1.55 & 0.03 & NS & NS & NS \\
\hline
\end{tabular}

\# 0-14 days after weaning; 0-24 days after weaning; DFI: daily feed intake; DWG: daily weight gain; F:G: feed:gain ratio.

${ }^{\text {a }}$ NT = normal Trp levels, as recommended by Rostagno et al. (2011); HT = high Trp levels (a 100\% higher level).

b Different upper case letters in the same row $(P<0.05)$ differ according to $F$ test.

c SEM: pooled standard error of the mean.

d NS: not significant $(P>0.05)$.

Maia et al. (2013), bedding substrates are the pig's preferred form of environmental enrichment because they induce foraging behaviors, such as oral manipulation, that are typical of this species, besides reducing undesirable behaviors such as fighting and biting, locomotion problems and improve the piglet's thermal and physical comfort.

On the other hand, it is harder to demonstrate positive responses on piglet's growth performance in such less challenging situations (from environmental and nutritional points of view) such as the one used in this study. Here, piglets were maintained in facilities with controlled temperatures and low occupation rates, in pens with beddings previously submitted to cleaning and disinfection, and fed a complex-diet containing antimicrobial agents such as zinc oxide and copper sulfate.

Absence of responses in DFI, DWG and F:G for animals receiving high TL diets $(5.2 \mathrm{~g} / \mathrm{kg}$ and $4.8 \mathrm{~g} / \mathrm{kg}$ in pre-starter I and II phases, respectively) could be due to a plateau effect of tryptophan over feed intake and protein deposition. The optimum levels for growth performance estimated by Jansman et al. (2010) were $2.3 \mathrm{~g}$ and $2.8 \mathrm{~g}$ of digestible $\mathrm{Trp} / \mathrm{kg}$ feed in pre-starter I and II diets, respectively. These values are close to $2.6 \mathrm{~g}$ and $2.4 \mathrm{~g}$ of digestible $\mathrm{Trp} / \mathrm{kg}$ feed in prestarter I and II diets, as proposed by Rostagno et al. (2011). Therefore, the lowest level of Trp used in this study would be sufficient to allow for an optimum growth performance. However, there is an energetic cost for the excess of Trp to be catabolized and excreted (Corzo, 2012). Thus, the choice of TL may interfere on animal performance and these results should be interpreted as inferences.

In contrast, Bruininx et al. (2002) found that 23L:1D program increased feed intake by $38.4 \%$ in the second week post-weaning compared to 8L:16D LP. Our results were different from them, probably due to the light periods that were studied. It is assumed that results with highest amplitude are found when periods of extreme lighting are compared. In this study, the shorter LP (12L:12D) was chosen as the minimum photoperiod because it is close to what is naturally found in most months in Brazil. The highest light period (23L:1D) is based on commercial farms common practice, who provide constant lighting in the first nursery days as a source of heat to promote piglet thermal
Table 5

Effects of light programs (LP) and Trp levels (TL) on average relative frequencies (\%) of "moving", "lying" and "feeding" behaviors for piglets in nursery phase at days $2,9,16$ and 23 after weaning.

\begin{tabular}{|c|c|c|c|c|c|c|c|c|}
\hline \multirow[t]{3}{*}{ Variable } & \multirow{3}{*}{$\begin{array}{l}\mathrm{LP} \\
12 / \\
\mathrm{NT}^{\mathrm{a}}\end{array}$} & \multirow{2}{*}{$\begin{array}{l}\text { LP } \\
12 / \\
\mathrm{HT}^{\mathrm{a}}\end{array}$} & \multirow{2}{*}{$\begin{array}{l}\text { LP } \\
23 / \\
\mathrm{NT}^{\mathrm{a}}\end{array}$} & \multirow{2}{*}{$\begin{array}{l}\text { LP } \\
23 / \\
\text { HT }^{\mathrm{a}}\end{array}$} & \multirow[t]{2}{*}{$\mathrm{SEM}^{\mathrm{c}}$} & \multicolumn{3}{|l|}{$P$-values } \\
\hline & & & & & & & & \\
\hline & & & & & & LP effect ${ }^{\mathrm{b}}$ & TL effect & $\mathrm{LP} \mathrm{P}^{* \mathrm{TL}}$ \\
\hline "Moving" & 9.8 & 9.8 & 10.4 & 9.6 & 2.5 & $\mathrm{NS}^{\mathrm{d}}$ & NS & NS \\
\hline "Lying" & $\begin{array}{l}77.8 \\
\text { a }\end{array}$ & $\begin{array}{l}76.6 \\
\mathrm{a}\end{array}$ & $\begin{array}{l}75.7 \\
\text { b }\end{array}$ & $\begin{array}{l}78.3 \\
\mathrm{a}\end{array}$ & 0.5 & NS & $<0.05$ & 0.02 \\
\hline "Feeding" & $\begin{array}{l}12.4 \\
\mathrm{aB}\end{array}$ & $\begin{array}{l}13.6 \\
\mathrm{a}\end{array}$ & $\begin{array}{l}13.9 \\
\text { aA }\end{array}$ & $\begin{array}{l}12.2 \\
\text { b }\end{array}$ & 0.9 & $<0.05$ & $<0.05$ & 0.005 \\
\hline
\end{tabular}

a NT = normal Trp levels, as recommended by Rostagno et al. (2011); HT $=$ high Trp levels (a 100\% higher level).

${ }^{\mathrm{b}}$ Different lower case letters within LP differ according to $F$ test $(P=0.023$ for Lying and $P=0.015$ for Feeding); Different upper case letters within NT level differ according to $F$ test $(P=0.03)$.

c SEM: pooled standard error of the mean.

${ }^{\mathrm{d}}$ NS: not significant $(P>0.05)$.

comfort.

The normal average blood glucose levels results $(89.67 \mathrm{mg} / \mathrm{dL})$ for piglets at the end of the experiment (day-28) may be related with a rapid adaptive response to the environment. Blood glucose rises as a secondary response to stress, aiming to keep the amount of energy necessary for maintenance of normal metabolic activity, and to support higher muscle demands in escape situations. In cases of chronic stress, blood glucose decreases progressively over time of exposure to the stress agent (Martínez-Miró et al., 2016). Accordingly, Puppe et al. (1997) reported that piglets exposed to an unfamiliar housing environment had higher plasma glucose levels compared to other animals exposed to a familiar housing environment immediately after weaning (day -1 vs day 1 ). Nevertheless, their plasma glucose returned to basal levels on the 4 th day post-weaning (day -1 vs day 4 ).

Table 4

Effect of light programs (LP) and dietary Trp levels (TL) on blood glucose and cortisol levels of piglets in nursery phase.

\begin{tabular}{|c|c|c|c|c|c|c|c|c|}
\hline Variable & $\mathrm{LP} 12 / \mathrm{NT}^{\mathrm{a}}$ & LP 12/HT & $\mathrm{LP} 23 / \mathrm{NT}^{\mathrm{a}}$ & $\mathrm{LP} 23 / \mathrm{HT}^{\mathrm{a}}$ & $\mathrm{SEM}^{\mathrm{c}}$ & \multicolumn{3}{|l|}{$P$-values } \\
\hline Blood glucose $(\mathrm{mg} / \mathrm{dL})$ at day-24 & 104.2 & 84.2 & 88.2 & 82.2 & 4.4 & $\mathrm{NS}^{\mathrm{d}}$ & NS & NS \\
\hline
\end{tabular}

${ }^{\text {a }}$ NT = normal Trp levels, as recommended by Rostagno et al. (2011); HT = high Trp levels (a 100\% higher level).

b Effect of LP (a,b); different lower case letters (x,y) within each LP differ according to $F$ test ( $P=0.03$ for $12 \mathrm{~h}$, and $P=0.0004$ for $23 \mathrm{~h}$ ); Different upper case letters $(\mathrm{A}, \mathrm{B})$ within NT level differ according to $F$ test $(P<0.0001)$.

${ }^{c}$ SEM: pooled standard error of the mean.

${ }^{\mathrm{d}}$ NS: not significant $(P>0.05)$. 
The plasma cortisol profile of domestic pigs can be modified by the photoperiod (Klemcke et al., 1989; Minton et al., 1989). Cortisol concentrations follows a circadian rhythm, the effect of luminosity is the pulsatile pattern to cortisol release that are higher during the light phase than during the darkness phase (Andersson et al., 2000). However, the circadian rhythm of cortisol can be altered or eliminated in situations of chronic stress (Janssens et al., 1995; Przekop et al., 1985). Melatonin reduces cortisol levels by inhibiting the supra-renal response to adrenocorticotropic hormone (Campino et al., 2011). Thus, increasing dietary TL, consequently increase serotonin and melatonin that may reduce the pig's cortisol levels and stress response (Meunier-Salaün et al., 1991; Sève et al., 1991).

The average plasma cortisol values found in this study are in agreement with Tuchscherer et al. (2014), who reported that plasma cortisol tripled in 7-, 21- and 35-day-old piglets exposed to social deprivation stress compared to control animals. On the other hand, higher levels of dietary Trp reduced cortisol in piglets receiving $23 \mathrm{~h}$ light/day to values close to those observed in animals receiving $12 \mathrm{~h}$ of light/day. These results suggest that Trp supplemented in levels that are optimal for growth performance is ineffective in stress mitigation. However, when the animal receives higher lighting levels (being therefore subjected to a lower melatonin production and higher stress), increased levels of Trp may reduce this type of stress response. Piglets submitted to $12 \mathrm{~h}$ of light/day had higher plasma cortisol contents when receiving high dietary TL. This is probably due to the higher stress generated by the need to catabolize the excess of Trp through TDO (tryptophan 2,3dioxygenase) by liver in order to prevent the toxic accumulation of this amino acid in plasma and tissues that may induce oxidative stress and lipid peroxidation (Forrest et al., 2004).

Increased stress may cause anomalous behaviors to emerge as an attempt to reduce the frustration, fear or monotony imposed by piglet weaning (Hemsworth and Coleman, 2011). Our experiments did not reveal an effect of the treatments on daily feed intake. Piglets exposed to $23 \mathrm{~h}$ of light/day and fed a diet with low TL had higher frequencies of "feeding" behaviors and lower frequencies of "lying behaviors" compared to those exposed to the same light regime but receiving a high TL. This indicates two things: that these piglets were potentially subjected to a higher stress and that a higher frequency of "feeding" behaviors may not always be related with feed intake.

Furlan et al. (1986) submitted growing and finishing pigs to natural $\mathrm{LP}$ of $18 \mathrm{~h}$ or $24 \mathrm{~h}$ of light/day. They found that animals had the same feed intake regardless of treatments and that the time required for that intake increased upon extended lighting. Christison (1996) submitted piglets to $5 \mathrm{~lx}$ or $100 \mathrm{~lx}$ lighting for 4 days after weaning found a higher frequency of "feeding" behaviors for animals exposed to $100 \mathrm{~lx}$. No effect on animal performance was observed.

Our results for frequency of "lying" behavior pigs show that they use to spending the majority of time resting and sleeping (which may reach $19 \mathrm{~h}$ per day in confined system). Animals receiving $23 \mathrm{~h}$ of light/day and fed a low TL diet had a lower frequency of "lying" behaviors. This shows that lighting puts animals in a more active state. However, this effect was softened when animals receiving 23-h of light/day were fed a diet with higher TL, possibly due to the tranquilizing action of Trp and its metabolites. Peeters et al. (2004) reported that pigs in the finishing phase receiving Trp supplementation in water spent more time lying during transportation to the slaughterhouse compared to those not receiving the same supplementation. Amaral et al. (2014) submitted pigs in the finishing phase to three daily LP during 28 days (natural light, 16L:8D, and 23L:1D) and reporting results with more active animals exposed to higher photoperiods similar to ours, failing to observe an improvement on growth performance.

Li et al. (2006) also reported that growing and finishing pigs receiving dietary TL two up to four times higher than those recommended by the NRC (1998) - $1.1 \mathrm{~g}, 2.3 \mathrm{~g}$ or $4.3 \mathrm{~g}$ Trp $/ \mathrm{kg}$ feed - spent more time lying down, less time standing up and had a lower frequency of "feeding" behaviors compared to those on control diet.
Koopmans et al. (2006) found that weaning piglets receiving diets supplemented with $5 \mathrm{~g}$ Trp/ $\mathrm{kg}$ feed displayed behavior alterations only after ten days, with reduced physical activity (less time standing up and more time lying down) compared to animals receiving the basal diet.

Martelli et al. (2015) analyzed the behavior, production parameters, quality of meat and of raw ham from Italian pigs ( $26 \mathrm{~kg}$ to $160 \mathrm{~kg} \mathrm{BW}$ ) submitted to two LP (8L:16D or 16L:8D) and to a $40 \mathrm{~lx}$ intensity. The authors found that if animals are provided with a proper dark resting period $(8 \mathrm{~h}$ ), increasing the photoperiod (even if at the threshold of $40 \mathrm{~lx}$ ) may positively influence growth parameters without negatively affecting behavior, carcass characteristics or meat/raw ham quality. In addition, the authors stated that the practice of raising pigs in darkness conditions should be considered unfounded and going against animal welfare. By associating these results with those found in our study, we hypothesize that the two analyzed photoperiods (23L:1D and 12L:12D) neither offer the darkness period necessary for the animals to rest concomitant with the bigger photoperiod duration possible.

The treatments used in the present work (high TL and $1 \mathrm{~h}$ of darkness) may have caused stress to the animals; thus, future studies should use intermediary TL and a 16L:8D photoperiod. In addition, assessing melatonin production, vitamin $\mathrm{C}$ metabolism and oxidative stress parameters may allow future studies to better understand the behavioral changes observed in weaning piglets.

\section{Conclusions}

Tryptophan supplementation and the use of light programs neither interfered with growth performance nor with blood glucose levels of weaning piglets. The photoperiod and Trp level in the diet modified the plasma cortisol profile and piglet behavior. The association between altered cortisol profile and higher activity for piglets receiving $23 \mathrm{~h}$ of light/day indicates that these animals were more active than shorter light period. However, this may be attenuated by the use of higher levels of dietary Trp. Providing $23 \mathrm{~h}$ of light/day or increasing dietary Trp level by $100 \%$ did not reduce or neutralize the negative effects of weaning on piglet's growth performance.

\section{Conflict of interest}

The authors confirm that no conflicts of interest are associated with this publication and no financial support was given that could have influenced the outcome of the present study.

\section{Funding}

This research did not receive any specific grant from funding agencies in the public, commercial, or not-for-profit sectors.

\section{Acknowledgement}

The authors acknowledge the support from Conselho Nacional de Desenvolvimento Científico e Tecnológico ( $\mathrm{CNPq}$ ) for the postgraduate student scholarship.

\section{References}

Adeola, O., Ball, R.O., 1992. Hypothalamic neurotransmitter concentrations and meat quality in stressed pigs offered excess dietary tryptophan and tyrosine. J. Anim. Sci. 70, 1888-1894.

Amaral, P.I.S., Ferreira, R.A., Pires, A.V., Fonseca, L.S., Gonçalves, S. A., Souza, G.H.C., 2014. Performance, behaviour and physiological responses of finishing pigs under different lighting programs. J. Anim. Behav. Biometeorol. 2, 54-59.

Andersen, I.L., Andenaes, H., Bøe, K.E., Jensen, P., Bakken, M., 2000. The effects of weight asymmetry and resource distribution on aggression in groups of unacquainted pigs. Appl. Anim. Behav. Sci. 68, 107-120.

Andersson, H., Lillpers, K., Rydhmer, L., Forsberg, M., 2000. Influence of light environment and photoperiod on plasma melatonin and cortisol profiles in young domestic boars, comparing two commercial melatonin assays. Domest. Anim. Endocrinol. 19, 
$261-274$

Bruininx, E.M., Van Der Peet-Schwering, C.M., Schrama, J.W., Vereijken, P.F., Vesseur, P.C., Everts, H., Den Hartog, L.A., Beynen, A.C., 2001. Individually measured feed intake characteristics and growth performance of group-housed weanling pigs: effects of sex, initial body weight, and body weight distribution within groups. J. Anim. Sci. 79, 301-308.

Bruininx, E.M., Heetkamp, M.J., Van den Bogaart, D., Van der Peet-Schwering, C.M., Beynen, A.C., Everts, H., Den Hartog, L.A., Schrama, J.W., 2002. A prolonged photoperiod improves feed intake and energy metabolism of weanling pigs. J. Anim. Sci. $80,1736-1745$

Campino, C., Valenzuela, F.J., Torres-Farfan, C., Reynolds, H.E., Abarzua-Catalan, L. Arteaga, E., Trucco, C., Guzmán, S., Valenzuela, G.J., Seron-Ferre, M., 2011. Melatonin exerts direct inhibitory actions on ACTH responses in the human adrenal gland. Horm. Metab. Res. 43, 337-342.

Christison, G.I., 1996. Dim light does not reduce fighting or wounding of newly mixed pigs at weaning. Can. J. Anim. Sci. 76, 141-143.

Corzo, A., 2012. Determination of the arginine, tryptophan, and glycine ideal-protein ratios in high-yield broiler chicks. J. Appl. Poult. Res. 21, 79-87.

Forrest, C.M., Mackay, G.M., Stoy, N., Egerton, M., Christofides, J., Stone, T.W., Darlington, L.G., 2004. Tryptophan loading induces oxidative stress. Free Radic. Res. $38,1167-1171$.

Furlan, A.C., Lima, J.A.F., Oliveira, A.I.G., Soares, M.C., Oliveira, B.L., 1986. Different lighting periods for growing and finishing pigs: experiment 1. Rev. Soc. Bras. Zootec. $15,372-377$.

Glatz, P.C., 2001. Effect of different lighting sources on behavior and growth of weanling pigs. Asian Australas. J. Anim. Sci. 14, 280-287.

Hemsworth, P.H., Coleman, G.J., 2011. Human-animal interactions and animal productivity and welfare. In: Hemsworth, P.H., Coleman, G.J. (Eds.), Human-Livestock Interactions: The Stockperson and the Productivity and Welfare of Intensively Farmed Animals. CABI, Cambridge, pp. 47-83.

Hötzel, M.J., Pinheiro Machado, F.L.C., Wolf, F.M., Dalla Costa, O.A., 2004. Behaviour of sows and piglets reared in intensive outdoor or indoor systems. Appl. Anim. Behav. Sci. 86, 27-39.

Hötzel, M.J., Machado Filho, L.C.P., Irgang, R., Alexandre Filho, L., 2010. Short-term behavioural effects of weaning age in outdoor-reared piglets. Animal 4, 102-107.

Hurnik, J.F., Webster, A.B., Siegel, P.B., 1995. Dictionary of Farm Animal Behavior, second ed. Iowa State University Press, Ames.

Jansman, A.J., Van Diepen, J.T., Melchior, D., 2010. The effect of diet composition on tryptophan requirement of young piglets. J. Anim. Sci. 88, 1017-1027.

Janssens, C.J., Helmond, F.A., Wiegant, V.M., 1995. The effect of chronic stress on plasma cortisol concentrations in cyclic female pigs depends on the time of day. Domest. Anim. Endocrinol. 12, 167-177.

Klemcke, H.G., Nienaber, J.A., Hahn, G.L., 1989. Plasma adrenocorticotropic hormone and cortisol in pigs: effects of time of day on basal and stressor-altered concentrations. Proc. Soc. Exp. Biol. Med. 190, 42-53.

Koopmans, S.J., Ruis, M., Dekker, R., Van Diepen, H., Korte, M., Mroz, Z., 2005. Surplus dietary tryptophan reduces plasma cortisol and noradrenaline concentrations and enhances recovery after social stress in pigs. Physiol. Behav. 85, 469-478.

Koopmans, S.J., Guzik, A.C., Van der Meulen, J., Dekker, R., Kogut, J., Kerr, B.J., Southern, L.L., 2006. Effects of supplemental L-tryptophan on serotonin, cortisol, intestinal integrity, and behavior in weanling piglets. J. Anim. Sci. 84, 963-971.

Li, Y.Z., Kerr, B.J., Kidd, M.T., Gonyou, H.W., 2006. Use of supplementary tryptophan to modify the behavior of pigs. J. Anim. Sci. 84, 212-220.

Maganhin, C.C., Carbonel, A.A.F., Hatty, J.H., Fuchs, L.F.P., Oliveira-Junior, I.S., Simões, M.J., Simoes, R.S., Baracat, E.C., Soares Jr., J.M., 2008. Melatonin effects on the female genital system: a brief review. Rev. Assoc. Med. Bras. 54, 267-271.

Maia, A.P.A., Sarubbi, J., Medeiros, B.B.L., Moura, D.J., 2013. Environmental enrichment as positive welfare of pigs: a review. J. Manag. Educ. Environ. Technol. 14, 2862-2877.

Mahan, D.C., 1991. Efficacy of initial postweaning diet and supplemental coconut oil or soybean oil for weaning swine. J. Anim. Sci. 69, 1397-1402.

Martelli, G., Nannoni, E., Grandi, M., Bonaldo, A., Zaghini, G., Vitali, M., Biagi, G., Sardi, L., 2015. Growth parameters, behavior, and meat and ham quality of heavy pigs subjected to photoperiods of different duration. J. Anim. Sci. 93, 758-766.
Martin, P., Bateson, P., 2008. Measuring Behaviour - An Introductory Guide, third ed. Cambridge University Press, Cambridge.

Martínez-Miró, S., Tecles, F., Ramón, M., Escribano, D., Hernandéz, F., Madrid, J., Orengo, J., Martínez-Subiela, S., Manteca, X., Cerón, J.J., 2016. Causes, consequences and biomarkers of stress in swine: an update. BMC Vet. Res. 12, 1-9.

Martínez-Trejo, G., Ortega-Cerrilla, M.E., Rodarte-Covarrubias, L.F., Herrera-Haro, J.G., Figueroa-Velasco, J.L., Galindo-Maldonado, F., Sánchez-Martínez, O., Lara-Bueno, A., 2009. Aggressiveness and productive performance of piglets supplemented with tryptophan. J. Anim. Vet. Adv. 8, 608-611.

Meunier-Salaün, M.C., Monnier, M., Colléaux, Y., Sève, B., Henry, Y., 1991. Impact of dietary tryptophan and behavioral type on behavior, plasma cortisol, and brain metabolites of young pigs. J. Anim. Sci. 69, 3689-3698.

Minton, J.E., Davis, D.L., Stevenson, J.S., 1989. Contribution of the photoperiod to circadian variations in serum cortisol and melatonin in boars. Domest. Anim. Endocrinol. 6, 177-181.

NRC - National Research Council, 1998. Nutrient Requirements of Swine, tenth ed. The National Academic Press, Washington.

Ning, L., Qian, L., 2008. Research progress on tryptophan requirement of piglets and growing and finishing pigs. Amino Sci. 2, 7-16.

Paredes, S.D., Barriga, C., Reiter, R.J., Rodríguez, A.B., 2009. Assessment of the potential role of tryptophan as the precursor of serotonin and melatonin for the aged sleepwake cycle and immune function: Streptopelia risoria as a model. Int. J. Tryptophan Res. 2, 23-36.

Peeters, E., Driessen, B., Steegmans, R., Henot, D., Geers, R., 2004. Effect of supplemental tryptophan, vitamin E, and a herbal product on responses by pigs to vibration. J. Anim. Sci. 82, 2410-2420.

Peltoniemi, O.A., Tast, A., Love, R.J., 2000. Factors effecting reproduction in the pig: seasonal effects and restricted feeding of the pregnant gilt and sow. Anim. Reprod. Sci. $60,173-184$.

Pereira, A.A., Donzele, J.L., Oliveira, R.F.M., Abreu, M.L.T., Silva, F.C.O., Martins, M.S., 2008. Dietary digestible tryptophan levels for barrows with high genetic potential in the phase from 97 to $125 \mathrm{~kg}$. Rev. Bras. Zootec. 37, 1984-1989.

Przekop, F., Stupnicka, E., Wolińska-Witort, E., Mateusiak, K., Sadowski, B., Domański, E. 1985. Changes in circadian rhythm and suppression of the plasma cortisol level after prolonged stress in the sheep. Acta Endocrinol. 110, 540-545.

Puppe, B., Tuchscherer, M., Tuchscherer, A., 1997. The effect of housing conditions and social environment immediately after weaning on the agonistic behaviour, neutrophil/lymphocyte ratio, and plasma glucose level in pigs. Livest. Prod. Sci. 48 , 157-164.

Reiners, K., Hessel, E.F., Sieling, S., Van den Weghe, H.F.A., 2010. Influence of photoperiod on the behavior and performance of newly weaned pigs with a focus on time spent at the feeder, feed disappearance, and growth. J. Swine Health Prod. 18, 230-238.

Rossi, L., Tirapegui, J., 2004. Serotoninergic system and its implications on physical exercise. Arq. Bras. Endocrinol. Metabol. 48, 227-233.

Rostagno, H.S., Albino, L.T.F., Donzele, J.L., Gomes, P.C., Oliveira, R.F., Lopes, D.C. Ferreira, A.S., Barreto, S.L.T., Euclides, R.F., 2011. Brazilian Tables for Poultry and Swine: Composition of Feedstuffs and Nutritional Requirements, third ed. Universidade Federal de Viçosa, Viçosa.

Sève, B., Meunier-Salaün, M.C., Monnier, M., Colléaux, Y., Henry, Y., 1991. Impact of dietary tryptophan and behavioral type on growth performance and plasma amino acids of young pigs. J. Anim. Sci. 69, 3679-3688.

Sousa Júnior, V.R., Abreu, P.G., Coldebella, A., Lopes, L.S., Lima, G.J.M.M., Sabino, L.A., 2011. Artificial illumination on performance of piglets at the nursery phase. Acta Sci. Anim. Sci. 33, 403-408.

Tuchscherer, M., Kanitz, E., Puppe, B., Hameister, T., Tuchscherer, A., 2014. Social support modulates splenocyte glucocorticoid sensitivity in piglets exposed to social deprivation stress. Physiol. Behav. 131, 25-32.

Van Hierden, Y.M., Koolhaas, J.M., Korte, S.M., 2004. Chronic increase of dietary Ltryptophan decreases gentle feather pecking behaviour. Appl. Anim. Behav. Sci. 89, 71-84.

Zhang, H., Yin, J., Li, D., Zhou, X., Li, X., 2007. Tryptophan enhances ghrelin expression and secretion associated with increased food intake and weight gain in weanling pigs. Domest. Anim. Endocrinol. 33, 47-61. 